\title{
Studies in Bomb Calorimetry. A New Determination of the Energy of Combustion of Benzoic Acid in Terms of Elec- trical Units
}

\author{
K. L. Churney and G. T. Armstrong
}

Institute for Basic Standards, National Bureau of Standards, Washington, D.C. 20234

(July 20, 1968)

\begin{abstract}
The heat of combustion of NBS Standard Sample 39i of benzoic acid under standard bomb conditions has been determined in terms of electrical units. A value of $-26,434.0 \mathrm{~J} \mathrm{~g}^{-1}$ was obtained. The total uncertainty in our determination is estimated to be $\pm 3.3 \mathrm{~J} \mathrm{~g}^{-1}$. The uncertainty due to random errors was $1.7 \mathrm{~J} \mathrm{~g}^{-1}$ and is based on the appropriate factors for the Student $t$ distribution at the 95 percent confidence limits for eleven determinations of the energy equivalent of the calorimeter and six determinations of the heat of combustion of benzoic acid. The principal systematic error, neglect of surface temperature correction for our calorimeter, has been assigned a value of $\pm 2.6 \mathrm{~J} \mathrm{~g}^{-1}$ until more reliable estimates of the correction can be made. Particular emphasis was placed on improving the precision of a calorimetric measurement over those previously obtained in this laboratory by the use of more sensitive auxiliary measuring equipment and more accurate procedures to evaluate the corrected temperature rise.
\end{abstract}

Key Words: Benzoic acid, heat of combustion; bomb calorimetry, procedures and errors; heat of combustion; bomb-calorimeter, electrical calibration; Dickinson calorimeter.

\section{Introduction}

Benzoic acid has served for many years as a reference material of known energy of combustion for calibrating bomb calorimeters. At the National Bureau of Standards (NBS), the Heat Division of the Institute for Basic Standards, or its predecessors, has certified the energy of combustion of various batches of benzoic acid in terms of electrical units for this purpose. Maintenance of a capability of a high degree of accuracy and precision in bomb calorimetry is a prerequisite for this certification activity.

The calorimetric measurements on which the certifications at NBS have been based have been made in most instances with a calorimeter of the same design, except for slight modifications, as that used by Dickinson [1]. ${ }^{1}$ In July of 1964, we started a study whose goal was to design a new bomb calorimeter capable of higher accuracy and precision than existing calorimeters. The first step in this project was a study of the performance of an existing Dickinson calorimeter (NBS 57662). The study was made in the hope that it would lead to a better understanding of the limitations inherent in the Dickinson calorimeter.

\footnotetext{
${ }^{1}$ Figures in brackets indicate the literature references at the end of this paper.
}

A second reason for making the study is that the last certification of benzoic acid in terms of electrical units at NBS was made in 1942 [2]. More recent certifications have been based upon intercomparison of benzoic acid samples. It appeared likely that a certification in terms of electrical units could now be made with greater accuracy than had been possible heretofore, because of the substantial improvement in the precision and accuracy of the auxiliary measuring instruments of the calorimetric station since 1942 . Although there was no reason to suspect that the intercomparisons of samples had introduced undetected systematic errors in the certification of batches of benzoic acid, we wished to confirm the absence of such errors.

The general features of the calorimeter and its method of operation have been adequately described elsewhere $[3,4,5]$. A summary of pertinent details is given in sections 2 and 4.

The basis for the correction of the observed temperature rise of the calorimeter for the effects of heat transfer from its environment, Newton's cooling law, and of stirring energy is found in the discussion of Coops, Jessup, and Van Nes [4]. The particular method of calculation used in this work is described in section 5 in some detail because of the higher accuracy obtained by the use of fewer approximations. 
Previous analysis of extensive calorimetric data from this laboratory had suggested that the uncertainty in our calorimetric measurements might be due mainly to the uncertainties in temperature measurements during the drift periods. Increasing the precision of the measurements of the resistance of the platinum thermometer led to a substantial improvement in the precision of measurement of the calorimeter temperatures but revealed the presence of small systematic deviations from Newton's cooling law. Modification of the calorimeter and our method of operating it suggested some possible explanations for these systematic deviations and reduced but did not entirely eliminate them as is discussed in sections $3,5.1 \mathrm{a}$, and 6.2 .

A series of electrical calibrations to determine the energy equivalent of the calorimeter and a series of benzoic acid combustions to determine the energy equivalent, in terms of electrical standards, of the combustion of benzoic acid are described in sections 4 and 5. Presentation of the results is completed in section 6 by an analysis of random and systematic errors.

\section{Experimental Apparatus}

The calorimetric apparatus consists of a stirredwater calorimeter surrounded by an isothermal jacket. The calorimeter consists of a closed can which contains a stirrer, a platinum resistance thermometer placed near the can wall, a combustion bomb with fuse leads and handle, an electrical heater that fits snugly around the lower half of the bomb, and a weighed, fixed, quantity of water sufficient to be in contact with the calorimeter lid after the calorimeter has been assembled. The calorimeter temperature is always kept below that of the jacket.

\subsection{Calorimeter and Jacket}

The calorimeter and jacket are essentially the same as described previously by Jessup [6], except for the following modifications.

The calorimeter jacket has been enclosed by an air bath, kept near $27.5^{\circ} \mathrm{C}$ with a regulation of $\pm 0.2{ }^{\circ} \mathrm{C}$ by an on-off controller. The air bath was required to make sure the average jacket temperature did not change with time. Thermocouple measurements had shown the lid (i.e., top) of the jacket was about $0.006^{\circ} \mathrm{C}$ colder than the rest of the jacket, presumably due to poor water circulation in the lid, when the room temperature was $3{ }^{\circ} \mathrm{C}$ below that of the jacket. The jacket temperature regulator was replaced by a commercially available proportional controller having reset action and a nickel resistance thermometer for a sensor.

To insure a constant stirring rate, the calorimeter stirrer was turned by a synchronous motor.

The oxygen combustion bomb and its internal fittings are those described previously [7], except for two changes. The fuses were made of $2 \mathrm{~cm}$ of 0.002 -in-diam platinum wire rather than a combustible metal to eliminate any energy contribution due to fuse combustion as described by Prosen [5]. The stem of the bomb needle valve was modified so that the inside of the bomb could be directly connected to the pressure gage of the oxygen manifold during filling, for a more accurate pressure measurement.

The calorimeter heater is an improved version of a type described previously [8]. It consists of a $32-\Omega$ heater element of glass-insulated, 0.010 -in-diam Advance wire which was soft soldered at both ends to 18-gage, Formvar-covered, copper, current leads. The element was inserted in a $3 / 16$-in-diam 0.030 -in-wall, soft copper tube. The tube was flattened against the element after the space between the tube and element was filled with epoxy-resin cement. The tube (sheath) length was selected so that, after the heater was coiled to fit the bomb, at least $20 \mathrm{~cm}$ of each current lead of the heater element was inside the calorimeter. The length of each current lead between the calorimeter and jacket was $5 \mathrm{~cm}$. Of the two 26-gage copper potential leads, one was attached to a current lead at the calorimeter boundary, the other to the remaining current lead at the jacket boundary.

Four jacket terminals pass through the jacket to "temper" thermally the heater leads (or fuse leads in the case of a benzoic acid combustion). They are the same as those described previously [9], except the electrical insulation was changed to a 0.008 -in-thick layer of Teflon tape and epoxy-resin cement. The insulation resistance both from the heater element to its tube sheath and from the jacket terminals to the jacket wall is greater than $100 \mathrm{M} \Omega$ at $100 \mathrm{~V}$.

\subsection{Calorimeter Temperature Measurement Equipment}

The platinum resistance thermometer is of the Meyers type of construction [10], having a 20-cm-long, 7-mm-diam Pyrex sheath, and an ice-point resistance of about $25.5 \Omega$. The resistance element is wound in a single coil very close to the glass sheath to provide fast response and to minimize self-heating. For these experiments the thermometer head was protected from thermal drafts by a cylindrical aluminum shield covered with asbestos and aluminum. The thermometer leads are connected to the bridge via a selector box. The thermometer was reproduceably inserted to a depth of $21 \mathrm{~cm}$ in the calorimeter can (height, $23 \mathrm{~cm}$ ).

The sensitivity of the measurement of the change in resistance of the platinum resistance thermometer was increased from $10^{-5} \Omega\left(10^{-4}{ }^{\circ} \mathrm{C}\right)$ to $10^{-6} \Omega\left(10^{-5}{ }^{\circ} \mathrm{C}\right)$. This was accomplished by replacing the $\mathrm{G}-2$ Mueller bridge (smallest dial unit $10^{-4} \Omega$ ) by a G-3 Mueller bridge (smallest dial unit $10^{-5} \Omega$ ) and using a more sensitive detector of the bridge imbalance.

The main features of the G-3 Mueller bridge are discussed briefly elsewhere [10]. Special shielding of the bridge and alteration of the heater supply for the bridge thermostat have been described previously [11]. 
Two galvanometer systems were used with the bridge. The new and more sensitive system consists of a photoelectric amplifier, having a taunt suspension galvanometer, and secondary galvanometer. A 1/2-mm deflection of the secondary galvanometer corresponded to a change in thermometer resistance of $1 \mu \Omega\left(1 \times 10^{-5}\right.$ ${ }^{\circ} \mathrm{C}$ ), with bridge current reversal and a thermometer current of $2 \mathrm{~mA}$. The less sensitive galvanometer system, essentially the same as that described previously [12], but with a somewhat more sensitive galvanometer, was used to measure the thermometer resistance only during the rapid temperature rise of the main period of an electrical calibration experiment.

\subsection{Ignition Energy Circuit}

The electrical energy required for ignition of the benzoic acid pellet was determined by measuring the voltage before (about $25 \mathrm{~V}$ ) and after (about $24 \mathrm{~V}$ ) the discharge of a capacitor having a measured capacitance of $(40.6 \pm 0.5) \times 10^{3} \mu \mathrm{F}$. The circuit is similar to that described by Boyd [13].

The fraction of the energy released by the capacitor that is dissipated in the part of the circuit external to the calorimeter was $0.25 \pm 0.10$. The first step in determining this number was to measure the corrected temperature rise caused by 50 complete discharges of the capacitor, when a short was connected across the fuse electrodes in the bomb interior. The fraction of energy dissipated external to the calorimeter for this particular experiment was calculated using the known capacitance, voltages, etc. The fraction dissipated in actual combustion experiment was calculated by combining this data with the measured lead resistances and the resistances between the bomb fuse terminals in the actual combustion experiments. The main source of the estimated uncertainty in the fraction is the assumption that the combustion fuse resistance does not change before it melts.

\subsection{Electrical Calibration Circuits}

The basic circuit for supplying electrical power to the heater has been described elsewhere [4].

Two separate, commercially available, Zenerdiode-stabilized, d-c power supplies were used to supply electrical energy to the heater. One unit, with a range of $0-2 \mathrm{~A}$ and $0-60 \mathrm{~V}$ and operated in the constant-voltage mode, was used to supply power at levels of 60 and $110 \mathrm{~W}$ to the heater. The other unit, having a range of $0-5 \mathrm{~A}$ and $0-105 \mathrm{~V}$ and operated either in the constant-current or constant-voltage mode, was used to supply power at $270 \mathrm{~W}$. The stabilities of these power supplies in the constant voltage mode was 2 to $10 \mathrm{ppm}$ as inferred from measurements of heater voltage. ${ }^{2}$ The relative equality and stability ( $1 \mathrm{yr}$ ) of the resistors are \pm 0.0015 percent and
\pm 0.0005 percent, respectively.

3 The other $1,000-\Omega$ resistor is used only when a volt-box ratio of $1: 100$ is required.
The time interval during which power is supplied to the heater was measured with a time counter accurate to within $\pm 0.0001 \mathrm{~s}$.

The heater current is determined by measuring the voltage across a Reichsanstalt-type, $0.01-\Omega$ standard resistor.

The potential drop across the heater is determined with a $1: 1000$ nominal voltage divider or volt-box connected to the heater potential leads.

The resistive elements of the volt-box are: (a) a commercially available unit consisting of ten ${ }^{2}$ equal $10,000-\Omega$ resistors and two $1,000-\Omega$ resistors hermetically sealed in an oil-filled box, and (b) a $100-\Omega$ standard resistor. Permanent copper links connect the $10,000-\Omega$ resistors in series with the parallel combination of one ${ }^{3}$ $1,000-\Omega$ resistor and the standard resistor. Movable shorting bars are used to connect the $10,000-\Omega$ resistors in parallel with this combination. The bars are made from copper, have a l-cm-square cross section, and mercury-wetted surfaces to make electrical connections.

The volt-box is calibrated by measuring the resistance of the $100-1,000-\Omega$ parallel combination and then the resistance of all the resistors connected in parallel. In calculating the volt-box ratio, use is made of the fact that, because of the close matching of the $10,000-\Omega$ resistors, the ratio of series to parallel resistance of the $10,000-\Omega$ resistor set is equal to $100: 1$ within $1 \mathrm{ppm}$ [14].

The imprecision of the volt-box ratio in 9 determinations made during the course of the electrical calibrations was $0.6 \mathrm{ppm}$ (standard deviation of a single determination). This is approximately the a priori estimated precision of a measurement. The inaccuracy was estimated to be between 2 and $10 \mathrm{ppm}$.

Potential measurements were made to $0.03 \mu \mathrm{V}$ with a six-dial double potentiometer using the more sensitive of the two galvanometer systems described in section 2.2. The range of the potentiometer extends to $0.111111 \mathrm{~V}$ in steps of $0.1 \mu \mathrm{V}$. The potentiometer voltage reference consisted of three saturated, Weston standard cells mounted in an improved version of a constant temperature box similar to one described previously [15]. Since both short- and long- (3 months) term temperature regulation of the box, as indicated by a platinum resistance thermometer in the cell compartment, was within $\pm 0.001{ }^{\circ} \mathrm{C}$, the standard cell voltage could be assumed to be constant to better than $1 \mathrm{ppm}$ during the course of the electrical calibrations (see sec. 5.3). The potentiometer interdial corrections were determined in the laboratory before and after the set of electrical calibration experiments. The potentiometer ratio was checked more frequently using an auxiliary circuit similar to that described elsewhere [16]. Its constancy, based on eleven determinations during the course of the electrical calibrations, was $1 \mathrm{ppm}$ (standard deviation of a determination).

The resistors of the auxiliary circuit and the volt-box as well as the standard current resistor were kept in a stirred-oil bath whose temperature was kept within $0.01^{\circ}$ of $33.16{ }^{\circ} \mathrm{C}$. At this temperature, the rate of 
change of the resistances with temperature is extremely small. Because of the constancy of the bath temperature, the resistance of the resistors could be assumed to be constant to better than $1 \mathrm{ppm}$ during the electrical calibration experiments.

The resistance ratios required in the calibration of the volt-box and potentiometer were measured with the Mueller bridge described in section 2.2.

\subsection{Oxygen Handling Equipment}

The oxygen manifold and associated purification equipment are essentially as described by Jessup [3]. A high-purity grade of commercially available oxygen ${ }^{4}$ was further purified for use in the benzoic acid combus. tions. The final oxygen pressure is measured to 0.01 atm on a calibrated Bourdon pressure gage. The temperature of the oxygen in the bomb is measured to the nearest $0.1{ }^{\circ} \mathrm{C}$ with a calibrated mercury thermometer inserted in a brass cup that fits snugly around the bomb while the bomb is being filled.

\section{Tests of the Apparatus}

Numerous measurements of the variation of the thermometer resistance with time during drift periods not associated with the principal calorimetric measurements showed that the imprecision of the measurements, as indicated by the average deviation of the observations from the best smooth curve drawn through the data, could be reduced to a few microohms. This was done by making resistance measurements at 1 min intervals with the bridge commutator set in alternately the $\mathrm{N}$ and then (i.e., next minute) in the $\mathrm{R}$ positions. Bridge current reversal and interpolation to $10^{-6} \Omega$ were made in the usual manner [17]. The effect of the time variation in the lead resistance was eliminated by calculating the resistance $R(t)$, at any time $t$, from the observed readings, adjusted for interdial corrections, $R^{\prime}(t), \quad R^{\prime}(t-1), \quad R^{\prime}(t+1)$ according to eq (1).

$$
R(t)=\frac{R^{\prime}(t-1)}{4}+\frac{R^{\prime}(t)}{2}+\frac{R^{\prime}(t+1)}{4} .
$$

Proper operation of the bridge commutator was critical in making these more precise measurements. This required replacing the mercury in the switch every three to six experiments and periodic reamalgamation of switch contacts.

Small systematic deviations of the best smooth curves drawn through the values of $R(t)$ from the resistance-time curves predicted by Newton's cooling law were observed. The shape of these deviation curves differed. A study of possible causes of the deviations was inconclusive. The changes in the calorimeter jacket, calorimeter stirrer motor, and the thermal

${ }^{4}$ Supplier's impurity analyses were 10.0, 84.0, 0.18, and 15.9 molar ppm for argon, nitrogen, water, and methane, respectively. shielding of the thermometer head, mentioned in section 2 , reduced but did not completely eliminate the deviations.

The stirring of the calorimeter was varied in order to test the possible effect of variation of the heat generated by stirring as a source of deviations. Although the study of this factor was incomplete, we found no clear evidence to indicate that random fluctuations of the energy of stirring of the water might cause deviations either when the stirrer was operated intermittently or when the stirrer was turning at a constant rate. The installation of a synchronous motor to turn the calorimeter stirrer was made to insure a constant rate. We did obtain some results suggesting that actual misalinement or flutter in the stirrer shaft might be a source of deviations.

To test the applicability of Newton's cooling law over a wider range of temperature than usually occurs in a drift period $\left(0.01{ }^{\circ} \mathrm{C}\right.$ or less), the average rate of change of the resistance of the thermometer was measured at six calorimeter temperatures below that of the jacket, 12 to 19 resistance measurements were made at each calorimeter temperature by the procedure given above. Resistances were averaged according to eq (1). The drift rate, $\Delta R(t) / \Delta t$, corresponding to a selected thermometer resistance, $R_{S}(t)$, was determined from the best straight line passing through the first order differences plotted as a function of time. The number of values of $R(t)$ at each calorimeter temperature, the value of $R_{S}(t), \Delta R(t) / \Delta t$ for the selected values of $R(t)$, and the estimated average deviation of the first order differences from the straight line are given in columns $1,2,3$, and 4 of table 1 .

TABLE 1. Calorimeter drift rate as a function of calorimeter temperature

\begin{tabular}{|c|c|c|c|c|}
\hline \multirow{2}{*}{$\begin{array}{c}\text { No. of values } \\
\text { of } R(t)\end{array}$} & \multirow{2}{*}{$R_{S}(t)$} & \multicolumn{3}{|c|}{$\Delta R(t) / \Delta t, \Omega \times 10^{6} \mathrm{~min}^{-1}$} \\
\hline & & "Obs" & Av. dev. & "Obs"-"Calc.", a \\
\hline 10 & 28.00717 & 568.7 & 0.5 & -0.8 \\
\hline 17 & 28.06315 & 460.7 & 0.7 & +0.7 \\
\hline 13 & 28.11692 & 355.0 & 0.6 & +0.2 \\
\hline 11 & 28.16559 & 260.0 & 0.7 & +0.4 \\
\hline 15 & 28.21188 & 169.0 & 0.4 & 0.0 \\
\hline 13 & 28.25985 & 74.7 & 0.5 & -0.5 \\
\hline
\end{tabular}

$\left(\frac{\Delta R(t)}{\Delta t}\right)_{\text {calc }}=1956.35(28.29828-R(t))$.

It may be shown that, if Newton's cooling law holds, $\Delta R(t) / \Delta t$ should be a linear function of $R(t)$ with an error of less than $3 \times 10^{-8} \Omega \mathrm{min}^{-1}$ in $\Delta R(t) / \Delta t$ for our calorimeter and resistance thermometer. The differences between the "observed" values and those calculated from a least squares fit of the data, assuming that $R(t)$ has negligible error in comparison to $\Delta R(t) / \Delta t$, are given in column 5 of table 1 . The root mean square deviation, $0.5 \times 10^{-6} \Omega \mathrm{min}^{-1}$, is substantially smaller than the value of $3.3 \times 10^{-6} \Omega \mathrm{min}^{-1}$ obtained previously by Jessup [18]. Some of the differences is due to the lower sensitivity of Jessup's resistance measure- 
ment $\left(10^{-5} \Omega\right)$ and some is due to the averaging effect of eq (1). ${ }^{5}$ In any event, the random deviations from Newton's cooling law appear to be substantially less than those obtained previously. This is consistent with an improvement in the calorimetric measurements which is discussed further in section 6.1.

A summary of the magnitudes and types of deviations from Newton's cooling law during drift periods of the calorimetric measurements themselves is given in section 5.1.

\section{Experimental Procedures}

\subsection{Benzoic Acid Combustions}

The general experimental procedure involved in a benzoic acid experiment closely follows that given by Jessup [19]. Significant differences are given below.

The benzoic acid received no special treatment prior to the experiment but was used as it came from the bottle of NBS standard sample'39i. Pellets of $1.51 \pm 0.015 \mathrm{~g}$ were prepared and accurately weighed after $1 / 2$-hr temperature equilibration in a platinum crucible in a balance having a readability of $1 \mu \mathrm{g}$.

After the bomb was filled to a pressure of $30 \mathrm{~atm}$ of oxygen, 15 to $20 \mathrm{~min}$ were allowed to elapse, to ensure temperature equilibration of the bomb and oxygen, before the final pressure and temperature were read.

The temperature of the calorimeter jacket was determined by measuring the resistance of the platinum resistance thermometer to $\pm 10 \mu \Omega$ as originally described in section 3 using bridge-current reversal.

Fifteen to $20 \mathrm{~min}$ after the calorimeter had been heated to a temperature about $3{ }^{\circ} \mathrm{C}$ below that of the jacket, measurements of calorimeter temperature were started. The preliminary calorimeter-temperature measurements with lower sensitivity were essential to establish the values of the drift rate and the differences between the readings with the commutator in the $\mathrm{N}$ and $\mathrm{R}$ positions as a preliminary step to the much more difficult measurements to follow. After 5 to $10 \mathrm{~min}$ of these readings, the galvanometer sensitivity was increased to permit measurements to $\pm 1 \mu \Omega$, and these more precise measurements were carried out for an initial period of at least $12 \mathrm{~min}$.

One minute after the final resistance measurement of the initial period, the fuse was ignited by discharging the capacitor and initial and final capacitor voltages were noted. Time-temperature measurements during the rapid temperature rise of the main period were made with the thermometer current reduced from $2 \mathrm{~mA}$ to $0.6 \mathrm{~mA}$.

After the change in thermometer resistance was less than $0.002 \Omega \mathrm{min}^{-1}$, resistance measurements at one minute intervals were resumed with alternate $\mathrm{N}$ and $\mathrm{R}$ commutator positions at a sensitivity of $\pm 10 \mu \Omega$. Measurements to $\pm 1 \mu \Omega$ sensitivity were started after the drift decreased to $0.000200 \Omega \mathrm{min}^{-1}$ and continued through the remainder of the main period (defined to end $20 \mathrm{~min}$ after ignition) and a final period of at least $12 \mathrm{~min}$. The jacket temperature was then remeasured as before.

Table 2 illustrates a typical set of resistance and time measurements made during a combustion experiment. The letters $\mathrm{N}$ and $\mathrm{R}$ refer to the bridge commutator settings. Columns labeled average resistance are values of $R(t)$ calculated by eq (1) using uncorrected rather than corrected dial readings. The course of the experiment with time can be readily followed by reference to table 2 while reading the foregoing text.

TABLE 2. Observations of time and thermometer resistance during a combustion experiment

\begin{tabular}{|c|c|c|c|c|}
\hline \multirow{2}{*}{ Time } & \multicolumn{2}{|c|}{ Resistance minus 28.0} & \multirow{2}{*}{$\begin{array}{l}\text { Average } \\
\text { resistance } \\
\text { minus } 28.0\end{array}$} & \multirow{2}{*}{ Drift } \\
\hline & $N$ & $R$ & & \\
\hline Min & Ohms & Ohms & Ohms & Ohms $\min ^{-1} \times 10^{6}$ \\
\hline 0 & 0.18169 & & & \\
\hline 1 & & 0.18241 & & \\
\hline 2 & .18296 & & & \\
\hline 3 & & .18368 & & \\
\hline $\begin{array}{l}4 \\
5\end{array}$ & .18422 & 18494 & & \\
\hline $\begin{array}{l}5 \\
6\end{array}$ & .185487 & .18494 & & \\
\hline 7 & & .186196 & & \\
\hline 8 & .186747 & & 0.186785 & \\
\hline 9 & & .187451 & .187412 & 627 \\
\hline 10 & .188000 & & .188037 & 625 \\
\hline 11 & & .188698 & .188661 & 624 \\
\hline 12 & . 189246 & & .189283 & 622 \\
\hline 13 & & .189943 & .189906 & 623 \\
\hline 14 & . 190492 & & 190527 & 621 \\
\hline 15 & & .191183 & .191148 & 621 \\
\hline 16 & .191733 & & .191769 & 621 \\
\hline 17 & & .192427 & .192389 & 620 \\
\hline 18 & 192967 & & 193005 & 616 \\
\hline 19 & & .193660 & .193622 & 617 \\
\hline 20 & 194199 & & .194235 & 613 \\
\hline 21 & & .194882 & .194849 & 614 \\
\hline 22 & .195434 & & .195465 & 616 \\
\hline 23 & & .196110 & .196076 & 611 \\
\hline 24 & .196659 & & .196686 & 609 \\
\hline 25 & & .197330 & & \\
\hline & Ignition & & & \\
\hline 26.2892 & .20 & & & \\
\hline 26.4802 & .21 & & & \\
\hline 26.5710 & .24 & . & & \\
\hline 26.6511 & .26 & & & \\
\hline 26.7207 & .28 & & & \\
\hline 26.7993 & .30 & & & \\
\hline 26.8762 & .32 & & & \\
\hline 26.9740 & .34 & & & \\
\hline 27.0828 & .36 & & & \\
\hline 27.2201 & .38 & & & \\
\hline 27.3731 & .40 & & & \\
\hline 27.4658 & .41 & & & \\
\hline 27.5742 & .42 & & & \\
\hline 27.7227 & .43 & & & \\
\hline 27.8993 & .44 & & & \\
\hline 28.1146 & .45 & & & \\
\hline 28.2697 & .455 & & & \\
\hline 28.4495 & .460 & & & \\
\hline 28.6790 & .465 & & & \\
\hline 29.0040 & .470 & & & \\
\hline 29.1801 & .472 & & & \\
\hline 29.3914 & .474 & & & \\
\hline 29.6697 & .476 & & & \\
\hline 29.8461 & .477 & & & \\
\hline 30.0682 & .478 & & & \\
\hline 30.2112 & .4785 & & & \\
\hline 30.3543 & .4790 & & & \\
\hline 30.4885 & .4795 & & & \\
\hline 30.7058 & .4800 & & & \\
\hline 30.9726 & .4805 & & & \\
\hline 31.1630 & .4808 & & & \\
\hline 31.4654 & .4812 & & & \\
\hline 32 & .48175 & & & \\
\hline 33 & & $0.482 ? 2$ & & \\
\hline 34 & .48241 & & & \\
\hline 35 & & .482614 & & \\
\hline
\end{tabular}


TABLE 2. Observations of time and thermometer resistance during a combustion experiment-Continued

\begin{tabular}{|c|c|c|c|c|}
\hline \multirow{2}{*}{ Time } & \multicolumn{2}{|c|}{ Resistance minus 28.0} & \multirow{2}{*}{$\begin{array}{l}\text { Average } \\
\text { resistance } \\
\text { minus } 28.0\end{array}$} & \multirow{2}{*}{ Drift } \\
\hline & $N$ & $R$ & & \\
\hline Min & Ohms & Ohms & Ohms & Ohms $\min ^{-1} \times 10^{6}$ \\
\hline 36 & .482584 & & & \\
\hline 37 & & & & \\
\hline 38 & .482684 & & & \\
\hline 39 & & .482830 & & \\
\hline 40 & .482769 & & & \\
\hline 41 & & .482915 & 0.482863 & \\
\hline 42 & .482854 & & .482906 & 43 \\
\hline 43 & & .483000 & .482948 & 42 \\
\hline 44 & .482938 & & .482989 & 41 \\
\hline 45 & & .483080 & .483031 & 42 \\
\hline 46 & .483024 & & .483074 & 43 \\
\hline 47 & & .483166 & .483116 & 42 \\
\hline 48 & .483107 & & 483158 & 42 \\
\hline 49 & & .483250 & .483200 & 42 \\
\hline 50 & .483192 & & .483241 & 41 \\
\hline 51 & & .483331 & .483282 & 41 \\
\hline 52 & .483274 & & .483323 & 41 \\
\hline 53 & & .483413 & .483364 & 41 \\
\hline 54 & .483355 & & .483405 & 41 \\
\hline 55 & & .483496 & .483446 & 41 \\
\hline 56 & .483437 & · & .483488 & 42 \\
\hline 57 & & .483580 & .483530 & 42 \\
\hline 58 & .483522 & & .483572 & 42 \\
\hline 59 & & .483664 & .483613 & 41 \\
\hline 60 & .483603 & & .483654 & 41 \\
\hline 61 & & .483746 & .483695 & 41 \\
\hline 62 & .483684 & & .483736 & 41 \\
\hline 63 & & .483830 & .483778 & 42 \\
\hline 64 & .483769 & & .483819 & 41 \\
\hline 65 & & .483908 & .483859 & 40 \\
\hline 66 & .483852 & & .483900 & 41 \\
\hline 67 & & .483989 & .483941 & 41 \\
\hline 68 & .483934 & & .483983 & 42 \\
\hline 69 & & .484076 & .484025 & 42 \\
\hline 70 & .484013 & & & \\
\hline
\end{tabular}

\subsection{Electrical Energy Measurements}

Much of the experimental procedure was similar to that outlined for the chemical heat measurements in the previous section. The procedure for making the electrical calibration measurements is essentially that outlined previously [4, 2].

The combustion bomb was prepared without a pellet or platinum fuse but contained the usual platinum crucible and the usual amounts of oxygen and water.

Just prior to a run, the temperature of the standard cell enclosure was measured. The emfs at the output leads of the volt-box and the $0.01-\Omega$ standard current resistor were measured before and after a run when no power was supplied to the heater to obtain values of the residual (thermal) emf of the circuit.

Thermometer-resistance measurements during the rapid temperature rise (i.e., while the electrical power was on) of the main period were made in the same manner as in the benzoic acid experiments. Measurements of the potentials at the output of the volt-box and across the current resistor which were 0.054 and $0.018 \mathrm{~V}$, respectively, for the $110 \mathrm{~W}$ calibration experiments were made between temperature measurements. (The time of each potential measurement was differentiated from those of the main period temperatures by actuating the timer-printer with the standard second signal to record two times, exactly $1 \mathrm{~s}$ apart, which bracketed the time of the corresponding measurement.)
In this way it was possible to obtain up to eight measurements of both the heater current and voltage during a 5 min heating period.

At frequent intervals during the course of the calibration experiments, the volt-box was calibrated, the potentiometer ratio was determined, and the constancy of the resistance of the $0.01-\Omega$ standard resistor was checked.

\section{Calculation of Results of Calorimetric Experiments}

A series of 6 benzoic acid combustion experiments and then a series of 16 electrical calibration experiments were carried out. The electrical calibration experiments are separated into three groups depending upon whether the amount of power supplied to the calorimeter heater was approximately 110,60 , or $270 \mathrm{~W}$.

\subsection{Calculations of the Corrected Temperature Rise}

Values of corrected temperature rises are listed for the appropriate experiments in tables 3 and $4 . \mathrm{Ob}$ served temperature rises were of the order of $2.82{ }^{\circ} \mathrm{C}$, and the correction due to heat transfer between the calorimeter and jacket was about 1.5 percent of this value.

\section{a. Treatment of Initial and Final Period Data}

The observed readings of the bridge during the initial and final periods, illustrated in table 2, were converted to ohms by applying the various bridge corrections and then averaging according to eq (1). Temperatures corresponding to each $R(t)$ were calculated by the Callendar equation [10]. The parameters in this equation that are characteristic of our thermometer were determined by the Temperature Section of the Heat Division, NBS.

The calorimeter temperatures, $\theta(I, J)$, for the initial $(I=0)$ and the final $(I=1)$ drift periods were fitted to the integral form of Newton's cooling law, eqs (2).

$$
\begin{gathered}
\theta(I, J)=C(I)+D(I) \cdot P(J) \\
P(J)=\left(1-e^{-K J}\right) K .
\end{gathered}
$$

In eq (2), $C(I)$ and $D(I)$ are different constants for each drift period, $J$ is the time of occurrence of the temperature relative to the start of the appropriate drift period, and $K$, the cooling constant of the calorimeter, is defined by eq (3).

$$
K=[D(0)-D(1)] /[C(1)-C(0)] .
$$

A consistent fit of the temperature-time data by eqs (2) and (3) was started by estimating values of $C(I), D(I)$, and $K$ from the first and last datum points of each drift period. Calculation of "improved" values 
TABLE 3. Benzoic acid combustion calculations

\begin{tabular}{c|c|c|c|c|c|c|c|c|c}
\hline \hline $\begin{array}{c}\text { Expt. } \\
\text { No. }\end{array}$ & Mass & $F \times 10^{6}$ & $\Delta \theta$ & $m_{s}(1+F) / \Delta \theta$ & $E^{i}(\mathrm{cont})$ & $\Delta E_{\mathrm{IGN}}$ & $-\Delta E\left(\mathrm{HNO}_{3}\right)$ & $A^{*}$ & $\frac{E(\mathrm{cal})}{\left(-\Delta E_{B}\right)}$ \\
\hline & & & & & & & & & \\
& & & & & & & & \\
& & & & & & & & \\
1 & 1.523394 & -189.8 & 2.849658 & 0.5344869 & +1.43 & +1.49 & +0.49 & -27.8 & 0.5344591 \\
2 & 1.507283 & -166.7 & 2.819376 & 0.5345267 & +1.79 & +1.60 & +0.52 & -39.3 & 0.5344874 \\
3 & 1.492242 & -166.9 & 2.791449 & 0.5344869 & +1.80 & +0.93 & +0.70 & -46.0 & 0.5344409 \\
4 & 1.493978 & -160.8 & 2.794708 & 0.5344880 & +1.88 & +1.23 & +0.58 & -46.6 & 0.5344414 \\
5 & 1.525560 & -157.2 & 2.853627 & 0.5345198 & +1.93 & +1.21 & +0.58 & -46.3 & 0.5344705 \\
6 & 1.501083 & -180.8 & 2.807857 & 0.5345043 & +1.57 & +1.38 & +0.52 & -33.8 & 0.5344705 \\
\hline
\end{tabular}

Average

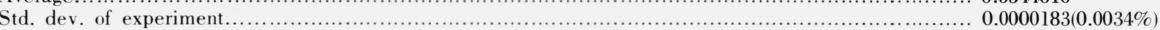

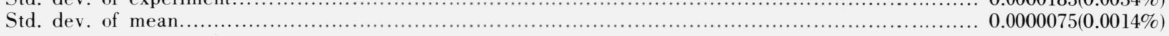

* $A=\left[\frac{\Delta E_{\mathrm{IGN}}-\Delta E\left(\mathrm{HNO}_{3}\right)}{(+\Delta \theta)}-E^{i}(\mathrm{cont})\right] \frac{1}{\left(-\Delta E_{k}\right)}$.

TABLE 4. Calculation of the energy equivalent of the calorimeter

\begin{tabular}{|c|c|c|c|c|c|c|c|}
\hline $\begin{array}{l}\text { Expt. } \\
\text { No. }\end{array}$ & $\begin{array}{c}\int_{0} E_{1} E_{l} d t \\
\left(p^{2} \mathrm{~s}\right) \times 10^{+3}\end{array}$ & $\begin{array}{c}\left(F_{2} / F_{1}\right) \int_{0} E_{r}^{2} d t \\
\left(p^{2} \mathrm{~s}\right) \times 10^{+3}\end{array}$ & $\begin{array}{c}Q_{T} / F_{1} \\
\left(p^{2} \mathrm{~s}\right) \times 10^{+3}\end{array}$ & $\begin{array}{c}Q_{e} \\
J\end{array}$ & $\begin{array}{l}\Delta \theta \\
{ }^{\circ} \mathrm{C}\end{array}$ & $\begin{array}{c}-E^{i} \text { (cont) } \\
J^{\circ} \mathrm{C}^{-1}\end{array}$ & $\begin{array}{l}E \text { (cal) } \\
J^{\circ} \mathrm{C}^{-1}\end{array}$ \\
\hline \multicolumn{8}{|c|}{ Heater power $110 \mathrm{~W}$} \\
\hline $\begin{array}{r}7 \\
8 \\
9 \\
10 \\
11 \\
12 \\
13 \\
14 \\
15\end{array}$ & $\begin{array}{l}3550.0634 \\
3559.4812 \\
3615.7432 \\
3605.5325 \\
3585.7557 \\
3591.6315 \\
3578.4748 \\
3591.6153 \\
3588.6870\end{array}$ & $\begin{array}{l}1.1258 \\
1.1288 \\
1.1467 \\
1.1434 \\
1.1372 \\
1.1390 \\
1.1348 \\
1.1390 \\
1.1381\end{array}$ & $\begin{array}{r}0.0377 \\
.0377 \\
.0378 \\
.0378 \\
.0378 \\
.0378 \\
.0378 \\
.0378 \\
.0378\end{array}$ & $\begin{array}{l}38,955.397 \\
39,058.739 \\
39,676.104 \\
39,564.063 \\
39,347.050 \\
39,411.526 \\
39,267.158 \\
39,411.348 \\
39,379.216\end{array}$ & $\begin{array}{l}2.757342 \\
2.764372 \\
2.808623 \\
2,800523 \\
2,785424 \\
2.789739 \\
2.779515 \\
2.789528 \\
2.787293\end{array}$ & $\begin{array}{l}0.30 \\
0.32 \\
0.39 \\
0.02 \\
0.20 \\
0.16 \\
0.16 \\
0.14 \\
0.14\end{array}$ & $\begin{array}{l}14,128.18 \\
14,129.66 \\
14,126.92 \\
14,127.40 \\
14,126.25 \\
14,127.48 \\
14,127.50 \\
14,128.46 \\
14,128.26\end{array}$ \\
\hline \multicolumn{8}{|c|}{ Heater power $60 \mathrm{~W}$} \\
\hline $\begin{array}{l}16 \\
17\end{array}$ & $\begin{array}{l}3575.0618 \\
3573.4132\end{array}$ & $\begin{array}{l}1.1342 \\
1.1337\end{array}$ & $\begin{array}{r}0.0069 \\
.0070\end{array}$ & $\begin{array}{l}39,229.362 \\
39,211.273\end{array}$ & $\begin{array}{l}2.776922 \\
2.775357\end{array}$ & $\begin{array}{l}0.07 \\
0.07\end{array}$ & $\begin{array}{l}14,126.99 \\
14,128.44\end{array}$ \\
\hline \multicolumn{8}{|c|}{ Heater power $270 \mathrm{~W}$} \\
\hline $\begin{array}{l}18^{*} \\
19^{*} \\
20^{*} \\
21^{*} \\
22\end{array}$ & $\begin{array}{l}3582.3213 \\
3548.3917 \\
3506.1535 \\
3588.2289 \\
3612.1828\end{array}$ & $\begin{array}{l}1.1348 \\
1.1240 \\
1.1107 \\
1.1368 \\
1.1440\end{array}$ & $\begin{array}{l}7.3177 \\
7.3241 \\
7.2380 \\
7.2382 \\
0.0208\end{array}$ & $\begin{array}{l}39,389.320 \\
39,017.047 \\
38,552.619 \\
39,453.237 \\
39,636.866\end{array}$ & $\begin{array}{l}2.788869 \\
2.762050 \\
2.729664 \\
2.792813 \\
2.805518\end{array}$ & $\begin{array}{l}0.13 \\
0.13 \\
0.16 \\
0.16 \\
0.19\end{array}$ & $\begin{array}{l}14,123.89 \\
14,126.25 \\
14,123.74 \\
14,126.86 \\
14,128.36\end{array}$ \\
\hline
\end{tabular}

*Constant current mode of power supply; all others constant voltage mode.

of these constants proceeded by computing the deviations, $F(I, J)$, of the "observed" temperatures from those calculated by eq (2) using the initial estimates of $C(I), D(I)$, and $K$. These deviations were fitted by least squares with deviation equations linear in $P(J)$ according to eq (4).

$$
F(I, J)=B(0, I)+B(1, I) P(J) .
$$

The values of $B(0, I)$ and $B(1, I)$ were used to correct the initial estimates of $C(I), D(I)$, and $K$. The cycle of calculations, performed by a high speed digital computer, was repeated until either the sum of the squares of the deviations of the initial and final drift periods increased or the values of $K$ calculated on two successive cycles differed less ${ }^{6}$ than $1 \times 10^{-7} \mathrm{~min}^{-1}$.

${ }^{6}$ The latter "stop" was inserted because there is no assurance of a distinct minimum in the sum of the squares of the deviations. It was, in fact, the terminating step of all the calculations after two or three iterations. The value of $1 \times 10^{-7} \mathrm{~min}^{-1}$ is based on the fact that the jacket temperature was constant to only about $1 \times 10^{-4}{ }^{\circ} \mathrm{C}$, and $K$ is approximately $2 \times 10^{-3} \mathrm{~min}^{-1}$
The observed temperature rise was computed from the calculated values of initial and final temperatures using eqs (2) and the final values of $C(I), D(I)$, and $K$.

This method of curve fitting assumes the values of $\theta(I, J)$ of each drift period are independent which cannot be so since the temperatures are calculated from observed resistances which were averaged according to eq (1).

It can be shown that, because of the use of eq (1), runs or deviations of the same sign should occur when the difference between "observed" and calculated temperatures are plotted as a function of time even though the errors are random. Usually, runs of three to five deviations of the same sign were observed. This indicates that in the case of random errors, those in the resistance measurements predominate. The systematic errors in the values of "observed" temperature and the calculated temperatures caused by using eq (1) are negligible.

Although the deviation plots sometimes showed systematic deviations from Newton's cooling law, they 
were small. The average root mean square deviation of "observed" from calculated values of $\theta(I, J)$ was slightly less than $2 \times 10^{-5}{ }^{\circ} \mathrm{C}$.

\section{b. Treatment of Main Period Data}

The correction to be added to the observed temperature rise due to heat transfer from the jacket and stirring energy is calculated according to a method discussed by Dickinson (see [20,4]). In this method, the main period data is used to evaluate the parameter $t_{x}$, defined by eq (5), and the remaining parameters are determined from the values of $C(I), D(I)$, and $K$ determined from the drift period data in section 5.1a.

$$
t_{x}=t_{f}-\frac{1}{\left(\theta_{f}-\theta_{i}\right)} \int_{t_{i}}^{t_{f}}\left(\theta-\theta_{i}\right) d t .
$$

In eq (5), $\theta_{i}$ and $\theta_{j}$ are the temperatures at the beginning, $t_{i}$, and end, $t_{f}$, of the main period, respectively.

To keep the error in the calculation of the correction to the observed temperature rise to $1 \times 10^{-5}{ }^{\circ} \mathrm{C}$ in our experiments, $t_{x}$ must be calculated to $0.1 \mathrm{~s}$ and the integral in eq (5) must be calculated with an accuracy of 1 part in 10,000. The following two procedures were adopted to minimize the calculation error.

First, the temperature-time data were graphed to eliminate gross errors and fill in gaps where data was sparse by superimposing corresponding portions of the main period of similar experiments.

Second, because eq (5) may be rewritten with an integral whose integrand is independent of temperature, temperatures of the main period were calculated in the same manner. Since virtually all the resistance measurements during the rapid temperature rise were made with fixed commutator position, the formula for the estimated correction for thermometer lead resistance applied to these readings was used throughout the main period. Thus, although the method of calculation of temperatures was in other respects the same as that for the initial and final periods, $\theta_{i}$ and $\theta_{f}$ in eq (5) are not quite the same as those used in calculating the observed temperature rise. We assumed the thermometer lead resistance correction varied linearly with the thermometer resistance in the main period from the average initial to the average final drift correction. Since the difference between these corrections was about $15 \mu \Omega$ for all the experiments, the net effect of an error in the assumption is negligible in comparison to other errors in the treatment of the data of the main period.

The integral in eq (5) was evaluated using the spline numerical integration procedure whose characteristics are described in detail elsewhere [21]. Essentially, the method fits a piecewise cubic with continuous first and second derivatives to the data. Calculations were carried out with a high speed computer using a program written in the Dartmouth BASIC language [22]. This program was based on a subroutine originally written in FORTRAN [23].

\subsection{Benzoic Acid Combustion Calculations}

Since benzoic acid is certified as a secondary heat standard for use in determining the energy equivalent of bomb calorimeters, it is convenient to express its energy of combustion per unit mass of benzoic acid under so-called standard bomb-conditions [4]. Determination of the energy of combustion of benzoic acid under standard bomb conditions, $\Delta E_{B}$, is carried out in two steps, the first of which is summarized in this section.

In order to compare the benzoic acid combustion data with the electrical calibration data, we defined the standard calorimeter to be the calorimeter can containing sufficient water so that their combined weight is $3750 \mathrm{~g}$, the calorimeter lid, the electrical heater, and the combustion bomb with its standard contents, its external fuse leads and its handle. The standard bomb contents were defined to be $1 \mathrm{~g}$ of water, the platinum crucible, platinum fuse, and 0.441 moles of oxygen $\left(30 \mathrm{~atm}\right.$ at $\left.25^{\circ} \mathrm{C}\right)$.

By selecting the temperature to which the isothermal bomb process is referred to be the final temperature the calorimeter would have if the heat transfer from the calorimeter environment and stirring energy were zero, the ratio of the energy equivalent of the standard calorimeter, $E(\mathrm{cal})$, in joules per degree, to $\Delta E_{B}$, in joules per gram, can be calculated from the experimental results by eq (6) (see [20], [5]).

$$
\begin{aligned}
\frac{E(\mathrm{cal})}{-\Delta E_{B}} & =\frac{(1+F) m_{s}}{\Delta \theta} \\
& +\left[\frac{\Delta E_{\mathrm{IGN}}-\Delta E_{\mathrm{HNO}_{3}}}{(\Delta \theta)}-E^{i}(\mathrm{cont})\right] \frac{1}{\left(-\Delta E_{B}\right)} .
\end{aligned}
$$

In eq (6), $\Delta \theta$ is the corrected temperature rise, $m_{s}$ is the mass (i.e., weight in vacuo) of benzoic acid in grams, $\Delta E_{\mathrm{IGN}}$ is the electrical energy supplied to the calorimeter to ignite the benzoic acid, $\Delta E_{\mathrm{HNO}_{3}}$ is the energy of formation of nitric acid produced in the actual combustion reaction, and $E^{i}$ (cont) is the correction added to $E$ (cal) to give the energy equivalent of the actual calorimeter prior to sample combustion. The quantity $F$ is related to the energy of combustion, $\Delta E_{B}^{\prime}$, per gram of benzoic acid under actual bomb conditions by eq (7).

$$
\Delta E_{B}^{\prime}=(1+F) \Delta E_{B}
$$

Numerical values of $F$ were calculated from the approximate formula given by Coops, Jessup, and Van Nes [4].

Since the second term on the right-hand side of eq (6) constitutes only a small contribution to the total, an approximate value of $\Delta E_{B}$ may be used in this term. For this we used $-26,434 \mathrm{~J} \mathrm{~g}^{-1}$. An error of $10 \mathrm{~J} \mathrm{~g}^{-1}$ in this value of $\Delta E_{B}$ would produce an error of only l ppm in $-E(\mathrm{cal}) / \Delta E_{B}$. 
A summary of the calculations is given in table 3 . In calculating $F$ (col. 3 ), the pressure of oxygen at $\theta_{h}$ was calculated from observed pressures using the equation of state for oxygen given by Coops, Jessup, and Van Nes [4]. E (cont), listed in column 5, was evaluated using $1.21 \mathrm{~J} \mathrm{~g}^{-1}{ }^{\circ} \mathrm{C}^{-1}$ [4] for the heat capacity of benzoic acid and a value of $21.17 \mathrm{~J} \mathrm{~mol}^{-1}[20]$ for the constant volume heat capacity of oxygen at $30 \mathrm{~atm}$. Measurement of $\Delta E_{I C, N}$ is summarized in section 2.3 and the determination of $\Delta E\left(\mathrm{HNO}_{3}\right)$ was made in the usual manner [4].

More accurate values of $F$ were calculated by evaluation of the Washburn correction by the procedure described by Hubbard, Scott, and Waddington [20] using the computer program developed by Shomate [24]. A very slight difference was observed in the $F$ values, for which a correction is made in the calculation of $\left(-\Delta E_{B}\right)$ at the bottom of table 5 . (The dispersion of the values of $E(\mathrm{cal}) /\left(-\Delta E_{B}\right)$ was not altered significantly.)

\subsection{Electrical Calibration Calculations}

The energy equivalent of the calorimeter, $E$ (cal), is related to the total electrical energy, $Q_{e}$, supplied to the calorimeter during a calibration experiment, by eq (8)

$$
Q_{e}=\left[E(\text { cal })+E^{i}(\text { cont })\right] \Delta \theta .
$$

In eq (8), $\Delta \theta$ is the corresponding corrected temperature rise and $E^{i}$ (cont) was defined in section $5 . Q_{e}$ was evaluated by eq (9)

$$
Q_{e}=F_{1} \int_{0}^{T} E_{\mathrm{l}} E_{l} d t-F_{2} \int_{0}^{T} E_{\imath}^{2} d t+Q_{T} .
$$

In eq (9) the various terms on the right are, respectively, the energy calculated from the potentiometer measurements, the correction for current passing through the volt-box, and correction for transients (i.e., any voltages not measured with the potentiometer). $E_{\mathrm{I}}$ and $E_{I}$ are the observed dial readings of the potentiometer at the output of the volt-box and across the current resistor, respectively after applying interdial and "zero" corrections. $T$ is the length of time power is supplied to the heater. $F_{1}$ and $F_{2}$ are constants which depend upon the volt-box ratio, resistance of the current resistor, the standard cell voltage, and the calibration of the potentiometer.

The numerical values of the terms on the right of eq (9) divided by $F_{1}$ are given in the first three columns of table 4. The unit $p$ in these tables stands for a "potentiometer unit" and is nominally $1 \mathrm{~V}$. The values of $Q_{e}, \Delta \theta, E^{i}$ (cont), and $E(\mathrm{cal})$ are listed in the remaining columns of table 4.

Because of the constancy of the volt-box and potentiometer ratios and the inferred constancy of the standard current resistor and standard cell voltage to $1 \mathrm{ppm}$ or better, $F_{1}$ and $F_{2}$ were assumed to be constants. This assumption causes negligible imprecision in $E$ (cal) as compared to that from other sources. The numerical values of $F_{1}$ and $F_{2}$ are $1.09765196 V^{2} \Omega^{-1} p^{2}$ and $1.099975 \times 10^{-4}$, respectively.

The standard cell voltage was determined by the NBS Electrochemistry Section of the Electricity Division by comparison with the NBS voltage standard. A correction of 1.4 microvolts [25] was added to this calibrated value since the average temperature of the cells during our measurements was $0.024{ }^{\circ} \mathrm{C}$ less than at the time the cells were calibrated.

The resistance of the standard current resistor was based on its certified resistance at $25^{\circ} \mathrm{C}$ and the temperature coefficient of its resistance as determined by the supplier. The maximum error in this calculated value of resistance at the oil bath temperature $(33.16$ ${ }^{\circ} \mathrm{C}$ ), as determined by ten potentiometric comparisons during the electrical calibration experiments of its resistance with that of a standard $0.1 \Omega$ resistor calibrated by the NBS Resistance and Reactance Section, was found to be 0.002 percent or less. After our measurements were completed, a more accurate value for the resistance was determined by the NBS Resistance and Reactance Section. The corresponding correction to the data was made in the final calculation of $\left(-\Delta E_{B}\right)$ in table 5 .

The first potentiometer measurements were made some 10 to $25 \mathrm{~s}$ after power was applied to the calorimeter heater. A total of 6,13 , and 2 measurements of $E_{V}$ or $E_{I}$ were made for the 110,60 , and $270 \mathrm{~W}$ experiments, respectively. Smoothed values of $E_{\mathrm{l}}$ and $E_{i}$ were obtained from separate plots of the observed values as a function of time; the time dependence, more or less unknown, of the $270 \mathrm{~W}$ measurements had to be inferred from other considerations [26]. Values of the integrals in eq (9) were computed with the spline integration subroutine of the computer program used in the calculation of the integral in eq (5).

After the electrical calibrations were completed it was found that large voltage transients occur when the power source supplying $270 \mathrm{~W}$ to the calorimeter heater in the constant current mode is switched from the dummy heater to the calibration circuit. These transients had disappeared well before the first measurements of $E_{V}$ and $E_{I}$ were made with the potentiometer. Subsequent examination of the voltage-time characteristics of this power source in the constant voltage mode and of the power source used to supply 110 and $60 \mathrm{~W}$ to the calorimeter heater in the constant voltage mode also indicated the presence of transients, but these were much smaller.

Numerical values of the energy supplied to the calorimeter by these transients are based on separate determinations of the transient voltage-time curves, as observed on an oscilloscope, for the power supplies operated in the appropriate mode of operation. Corrections to account for the slightly different average values of power supplied to the heater in the actual electrical calibrations were made assuming the length of time required to switch the power supply from the dummy to the calorimeter heater was constant. 
TABLE 5. Summary of calculation of $\left(-\Delta \mathrm{E}_{\mathrm{B}}\right)$

\begin{tabular}{|c|c|c|c|c|c|c|}
\hline $\begin{array}{l}\text { Expt. } \\
\text { No. }\end{array}$ & $\begin{array}{l}\text { Number of } \\
\text { expts. }\end{array}$ & Heater power & Average $E(\mathrm{cal}), J^{\circ} \mathrm{C}^{-1}$ & $\begin{array}{l}\text { Standard deviation of an } \\
\text { experiment, } J{ }^{\circ} \mathrm{C}^{-1}\end{array}$ & $\begin{array}{l}\text { Standard deviation of } \\
\text { average, } J^{\circ} \mathrm{C}^{-1}\end{array}$ & $\begin{array}{l}\text { 95\% confidence limits } \\
J^{\circ} \mathrm{C}^{-1}\end{array}$ \\
\hline $\begin{array}{l}7-15 \ldots \ldots \ldots \ldots \ldots \\
16-17 \ldots \ldots \ldots \ldots . \\
18-21 \ldots \ldots \ldots \ldots \\
22 \ldots \ldots \ldots \ldots \ldots \ldots \\
\text { Adopted value. }\end{array}$ & $\begin{array}{l}9 \\
2 \\
4 \\
1\end{array}$ & $\begin{array}{l}110 \mathrm{~W} \text { (constant voltage } \\
60 \mathrm{~W}(\text { constant voltage }) . . \\
270 \mathrm{~W}(\text { constant current }) . \\
300 \mathrm{~W}(\text { constant voltage }) . .\end{array}$ & $\begin{array}{l}14,127.79 \\
14,127.72 \\
14,125.19 \\
14,128.36 \\
14,127.79\end{array}$ & $\begin{array}{l}0.99(0.007 \%) \\
0.99 \\
1.6 \\
\ldots \ldots \ldots \ldots \ldots \\
0.99(0.007 \%)\end{array}$ & $\begin{array}{l}0.33 \\
0.73 \\
0.80 \\
\ldots .30\end{array}$ & $\begin{array}{l}0.76 \\
1.60 \\
2.55 \\
\ldots .68\end{array}$ \\
\hline
\end{tabular}

Summary of benzoic acid combustions

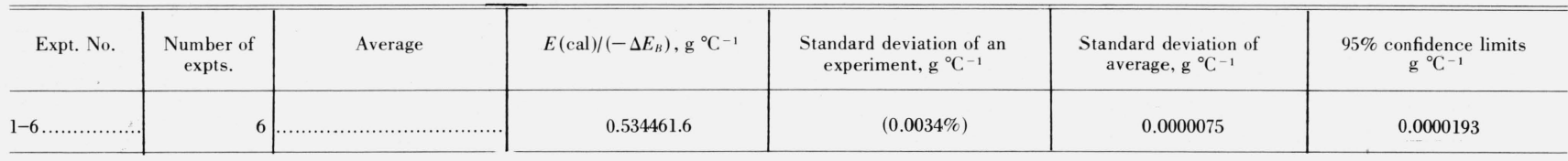

Calculation of $-\Delta \mathrm{E}_{\mathrm{B}}$

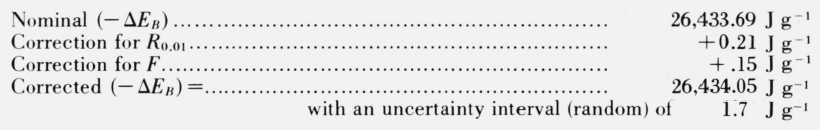

\subsection{Summary of results}

The calculations of the energy equivalent of the calorimeter are summarized at the top of table 5 . Ninety-five percent confidence limits are calculated by multiplying the standard deviation of the mean by the appropriate factor of the Student $t$-distribution. Assuming equal precision, standard deviations computed for experiments $7-15$ and for 16-17 are pooled together. Comparison of the average values of $E(\mathrm{cal})$ listed in table 5 for the three heater powers used in experiments 7 through 21 show they lie within their combined uncertainty (random) intervals. However, the results of experiments 18-22 were not used in computing a weighted average for $E$ (cal) for the following two reasons.

First, it will be noted from columns 2 and 4 of table 4 that the contribution of $Q_{T}$ to $E(\mathrm{cal})$ is 0.2 percent in the case of experiments 18-21. For the other experiments, the power supplies were operated in the constant voltage mode and the contribution of $Q_{T}$ to $E$ (cal) is less than 0.0012 percent. Since we feel that a systematic error in the estimate of $Q_{T}$ of 20 percent is not unreasonable, the difference between the average $E$ (cal) of experiments $18-21$ and the remainder is probably caused by a systematic error due at least in part to the error in $Q_{T}$.

Second, it will be noted that experiments 18-22 were carried out with the highest heater power and, thus, the shortest time necessary to warm the calorimeter $3{ }^{\circ} \mathrm{C}$. This resulted in the unfortunate situation that we were able to make only a few measurements of heater current or voltage when the change in voltage, or current, was the most rapid. We feel the uncertainty introduced in $E$ (cal) by the uncertainty in our estimates of the time dependence of the voltage, or current may be appreciable. Thus, the agreement of experiment 22 with $7-17$ is regarded as being somewhat fortuitous. Experiment 22 was given zero weight on the basis that we suspect its uncertainty is considerable larger than experiments $7-17$.

The results of the benzoic acid combustions and the value determined for $\Delta E_{B}$ for benzoic acid are summarized at the bottom of the table 5 . The precision of $\Delta E_{B}$ was calculated as suggested by Rossini [27]; the contribution of the imprecision due to the various factors taken as constants in determining $E$ (cal) was neglected since it was estimated to be $10 \mathrm{ppm}$.

\section{Appraisal of Experimental Results}

\subsection{Random Errors}

The standard deviation of a single combustion experiment with this particular calorimeter had never before been lower than 0.012 percent, for an extended series of measurements. It is clear from table 5 that the precision of the present measurements is substantially better than the previous work.

We were particularly interested to see whether or not we could account for the standard deviation of a measurement of either $-E(\mathrm{cal}) / \Delta E_{B}$ or $E(\mathrm{cal})$ in terms of the various factors we might expect to vary from experiment to experiment.

Common to both sets of measurements were the uncertainty in the corrected temperature rise and the absence of a buoyancy correction to the weight of the water placed in the calorimeter can.

The uncertainty in the corrected temperature rise was evaluated from the variances of the estimates of the various parameters appearing in eqs (2) and (3), using the usual propagation of error formulas [27] and assuming that the "average" root mean square deviation of $\theta(t)$ for the initial and final drift periods 
may be treated as a random error. These "averages" were arbitrarily multiplied by $\sqrt{2}$ since they are probably too small due to the use of eq (1) (see sec. 5.1a). The error in the integrai in eq (5) was based on the approximations that the main error is contributed by the errors in the times recorded during the rapid temperature rise of the main period and that the integral may be computed by the trapezoidal rule.

The uncertainty due to the absence of the buoyancy correction in the calorimeter weight was estimated from the known variation in air density during the benzoic and experiments $\left(12 \mathrm{mg} / \mathrm{l}^{7}\right)$ and the approximate volume of the calorimeter can plus water $(2.59$ l). The resulting percentage error was arbitrarily multiplied by two because it is quite evident from the method used to adjust the weight of water in the can (see [3]) that the aforementioned variation in air density is a minimum estimate. Other factors, such as convection currents, may also make a substantial contribution to the weighing error.

The random error in $E$ (cal) $/ \Delta E_{B}$ due to the uncertainty of the mass of the benzoic acid sample is based on a conservative estimate of $\pm 10 \mu \mathrm{g}$ for a sample weight of $1.5 \mathrm{~g}$.

The estimates of the varous errors contributed by the parameters which make up $F_{1}$ are based on the deviations of their measurements. The standard current resistor, $R_{0.01}$, was assumed to have a stability of $2 \mathrm{ppm}$.

The estimate of the random error in $E(\mathrm{cal})$ due to the random error in the integrals in eq (9) was based on the approximation that 13 smoothed pairs of values of $E_{V}$ and $E_{I}$ separated by $30 \mathrm{~s}$ time intervals were numerically integrated by the trapezoidal rule. The errors in the smoothed values of $E_{V}$ and $E_{I}$ were taken as $\pm 2 \times 10^{-7}$ potentiometer units.

The estimate of the random error due to the heater leads is based on the analysis given by Ginnings and West [28]. The dimensionless parameters $L_{s}$ and $L_{c}$ of that analysis were calculated to be 0.34 and 0.28 , respectively. The variation in the heater lead resistance was estimated to be $\pm 0.002 \Omega$; the heater resistance is $32 \Omega$.

A summary of the errors and a comparison with the observed standard deviation of an experiment is given in table 6 . The discrepancy between the observed and

\footnotetext{
${ }^{7}$ Square root of the sum of squares of the deviations divided by the number of measurements minus one.
}

estimated values for the electrical calibrations is probably greater than the uncertainty of our estimates.

\subsection{Systematic Errors}

One of the main assumptions customarily made in using a stirred-water "isoperibol" calorimeter is that the correction to the temperature rise due to heat transfer from the calorimeter jacket and heat delivered by the stirrer can be computed from Newton's cooling law and temperatures measured inside the calorimeter.

It is generally understood that this assumption would be valid if the calorimeter temperature were strictly uniform throughout the calorimeter. ${ }^{8}$ Real calorimeters have, of course, temperature gradients or, equivalently, temperature differences due to the effects of lags. Thus, the surface temperature of the calorimeter, which determines the rate of heat transfer between the calorimeter and jacket, is in general different from that measured by the thermometer, even though it is placed as close to the calorimeter wall as is practical.

The effect of a temperature gradient on calorimetric measurements has been analyzed to some extent for "isoperibol" calorimeters $[29,30,31]$, and in detail for aneroid adiabatic calorimeters [32]. Harper [29] has shown that if the lag of the temperature measurement system (i.e., including both thermometer and electrical detecting system) is the same throughout a calorimeter experiment then the lag causes no error in the corrected temperature rise. White [30], in effect, considers the temperature gradient to be the superposition of those due to (1) heat transfer from the jacket and stirring, and (2) heat released in the calorimeter during the main period. By an argument identical to that used by Harper, he showed that the lag due to the first of these sources causes no error in the corrected temperature rise, while the lag due to the second source will cause an error. However, if the latter lag is a constant which is independent of the source of heat (i.e., electrical heater or combustion bomb), then it will cause no error in the heat of combustion of benzoic acid. White felt that the constancy of the lag due to different heat sources could be verified by appropriate experiments.

${ }^{8}$ Convective heat transfer between the calorimeter and jacket must also be negligible. For this discussion, we assume this is so.

TABLE 6. Estimated random errors in $-\mathrm{E}(\mathrm{cal}) /\left(-\Delta \mathrm{E}_{\mathrm{B}}\right)$ and $\mathrm{E}(\mathrm{cal})$

\begin{tabular}{|c|c|c|}
\hline & $\begin{array}{c}\text { Benzoic acid } \\
\left(-E(\text { cal }) / \Delta E_{B}\right)\end{array}$ & $\begin{array}{c}\text { Electrical calibrations } \\
(-E \text { (cal)) }\end{array}$ \\
\hline & $\%$ & $\%$ \\
\hline 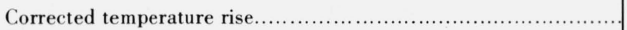 & 0.0022 & 0.0019 \\
\hline 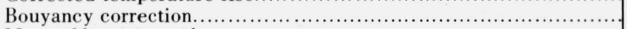 & 0.0018 & 0.0018 \\
\hline 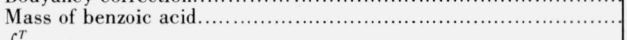 & 0.0007 & .......... \\
\hline 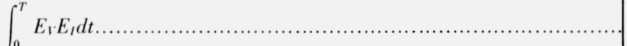 & & 0.0003 \\
\hline$h / E_{s c}^{\prime} \ldots \ldots \ldots$ & .............. & 0.0001 \\
\hline$E_{s c}$ & 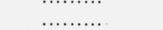 & 0.0001 \\
\hline 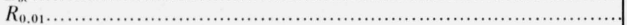 & ........... & 0.0002 \\
\hline Volt box ratio:........................... & ............. & 0.0001 \\
\hline 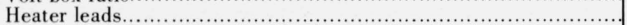 & & 0.0005 \\
\hline Estimated standard deviation of a measurement........................ & 0.0030 & 0.0027 \\
\hline Observed standard deviation of a measurement............................. & 0.0034 & 0.0070 \\
\hline
\end{tabular}


TABLE 7. Summary of values of $\left(-\Delta \mathrm{E}_{\mathrm{B}}\right)$ for benzoic acid

\begin{tabular}{|c|c|c|c|}
\hline Author & Sample & Value & Uncertainty \\
\hline Jessup and Green $[2,18,33]$ (1934). & $39 \mathrm{~d}, 39 \mathrm{e}$. & $\begin{array}{l}J g^{-1} \\
26,432.0\end{array}$ & $J^{J g^{-1}}+2.6$ \\
\hline Prosen and Rossini [35] $(1939-41) \ldots$ & $39 \mathrm{e} \ldots \ldots \ldots \ldots$ & $26,434.7$ & \pm 2.2 \\
\hline 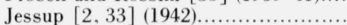 & $39 \mathrm{e}, 39 \mathrm{f}, \mathrm{B} \ldots$ & $26,433.8$ & \pm 2.6 \\
\hline Coops et al. [31] $(1946-8) .$. & $39 \mathrm{~b}, 39 \mathrm{f}$, VUS & $26,438.0$ & \pm 4 \\
\hline Coops et al. $[31](1954) \ldots \ldots$ & $39 \mathrm{~b}$, VUS ....... & $26,435.0$ & \pm 4 \\
\hline Challoner et al. [34] (1954)... & $\mathrm{C} . \ldots \ldots \ldots \ldots \ldots$ & $26,436.0$ & \pm 4 \\
\hline This work $(1966) \ldots \ldots \ldots \ldots \ldots \ldots$ & $39 \mathrm{i} \ldots \ldots \ldots \ldots$ & $26,434.0$ & \pm 3.3 \\
\hline
\end{tabular}

Coops et al. [31], have suggested one method of making the lag due to different heat sources the same and have incorporated this in the design of their calorimeter.

An experimental test that has frequently been applied is that the lag is a constant if it can be shown that the energy equivalent of the calorimeter is invariant with the power supplied to the electrical heater. This criterion has been shown to be incorrect by West [32] for a calorimeter in which heat flow equations are linear. It is interesting to note that part of this argument depends upon showing that the contributions to the correction on the observed temperature rise of the temperature transients due to turning the electrical heater on and off exactly cancel. Indirect evidence that this cancellation is the case for our calorimeter is given in section 7 . This conformity of our calorimeter with West's analysis of behavior of transients suggests that the remainder of West's argument may be applicable to the Dickinson calorimeter. The invariance of the energy equivalent found in the electrical experiments with varying electrical power (see table 5), thus, does not provide information about possible systematic errors.

A series of tests was carried out to see whether or not measurements based on the average surface temperature of the calorimeter in place of that registered by the platinum thermometer would give a different value of $\Delta E_{B}$ for benzoic acid. On the basis of these tests, which must be considered to be preliminary in nature, it was found that there is a difference between the temperatures of the calorimater surface and the water in the vicinity of the resistance thermometer and that this difference varies with time in the electrical calibrations in a different way than in the benzoic acid experiments. Because of certain experimental difficulties, we assigned an uncertainty to the difference in values of $\Delta E_{B}$ calculated from these observations that was about the same as the magnitude of the difference. Until a more reliable estimate based on more accurate tests is obtained, we have somewhat arbitrarily assigned an uncertainty of \pm 0.01 percent of $\Delta E_{B}$ to take into account the possible correction for the effect of surface temperature.

The net contribution of other sources of systematic errors in the electrical calibrations is estimated to be at most \pm 0.004 percent of $\Delta E_{B}$.

\subsection{Discussion of Results}

In table 7 , we have listed the more recent determinations of $\left(-\Delta E_{B}\right)$ for benzoic acid in joules per gram of sample. ${ }^{9}$ Samples indicated by the number 39 followed by a letter refer to batches of the benzoic acid standard sample issued by NBS. B refers to a sample of $39 \mathrm{e}$ purified by fractional crystallization from benzene. VUS and $\mathrm{C}$ refer to benzoic acid samples from sources other than NBS and are described in the corresponding references.

Uncertainty intervals listed in table 7 are those cited by the authors except for the work of Jessup and Green $[2,18,33]$ which we assumed to be equal to the later work of Jessup [2]. The bounds for the uncertainty interval for our own work was computed by the procedure recommended by Rossini [27] as $\sqrt{(1.7)^{2}+(1.1)^{2}+(2.6)^{2}}$.

Aside from our own work, only that of Challoner, Gundry, and Meetham [34] incorporates an uncertainty due to the effect of surface temperature. In the latter, a correction of $-0.046 \pm 0.0057$ percent had to be applied to the energy equivalent of the calorimeter to correct for the difference in surface temperature effects during the main period of an electrical calibration and a benzoic acid combustion experiment. Our preliminary experiments suggest that the magnitude of the surface temperature correction is not insignificant for our results although it is smaller than that of Challoner et al. A substantial contribution to the uncertainty of our results has been allowed because of the unknown magnitude of our surface temperature correction. It would be preferable, in spite of the difficulty of measuring it, to evaluate the correction experimentally in absolute calorimetric measurements unless the calorimeter has been specifically designed to eliminate the error.

\footnotetext{
${ }^{9}$ We have been informed by private communication from Mosselman and Dekker [36], and from Head [37], of very recent electrical determinations of the energy of combustion of benzoic acid in their respective laboratories. These determinations are both based on measurements made in calorimeters containing water flow channels of the type devised by Coops et al. [31], and both are reported to be in excellent agreement with the value we list for this work in table 7. The work of Mosselman and Dekker includes some measurements on NBS Standard Sample 39i.
} 


\section{Appendix. Analysis of Main Period of the Electrical Calibration Experiments}

If the temperature transients due to turning the electrical heater on and off make no net contribution to the corrected temperature rise, the two areas between the main period curves of the electrical calibrations and the straight lines given by eqs (10a), (10b), and (10c) should be equal since the heater power does not vary with time.

$$
\begin{array}{ll}
\theta(t)=\theta_{i}+(d \theta / d t)_{i}\left(t-t_{i}\right) ; & t_{i} \leqslant t \leqslant t_{1} \\
\theta(t)=\theta_{3}+(d \theta / d t)_{3}\left(t-t_{3}\right) ; & t_{1} \leqslant t \leqslant t_{2}+t_{b} \\
\theta(t)=\theta_{f}+(d \theta / d t)_{f}\left(t_{f}-t\right) ; & t_{2}+t_{b} \leqslant t \leqslant t_{f} .
\end{array}
$$

Equations (10a) and (10c) are linear extrapolations of the initial and final drift period curves into the main period, and the constants $\theta_{3}, t_{3}$ and $\left(\frac{d \theta}{d t}\right)_{3}$ of eq (10b) are determined from a linear least squares fit of the main period data during the rapid temperature rise. The times $t_{1}$ and $t_{2}+t_{b}$ are the times of intersections of eq (10b) with eq (10a) and (10c).

To test whether or not the areas are equal, we noted that if they are, then the time $t_{1}$ should be approximately equal to time ${ }^{10} t_{b}$ and both should be independent of the power supplied to the heater or $(d \theta / d t)_{3}$. Comparison of columns 3 through 5 of table 8 shows this is very nearly true. Further, the equality of the areas means that the integral in eq (5) for $t_{x}$ is the area enclosed by the lines of eqs (10a) through (10c) and $\theta_{i}$. Corrected temperature rises computed using values $t_{f}-t_{x}$ determined in this manner differed by less than one part in $10^{5}$ from those listed in section 5 . The latter are based on values of $t_{f}-t_{x}$ determined by

\begin{tabular}{|c|c|c|c|c|c|c|}
\hline $\begin{array}{c}\text { Heater power } \\
\text { watts }\end{array}$ & $\begin{array}{l}\text { No. of } \\
\text { Expts. }\end{array}$ & $\begin{array}{c}t_{1} \\
\min \end{array}$ & $\begin{array}{c}t_{b} \\
\min \end{array}$ & $\begin{array}{l}(d \theta / d t)_{3} \\
{ }^{\circ} \mathrm{C} \min ^{-1}\end{array}$ & $\underset{t_{2}}{t_{2}}$ & $\begin{array}{l}t_{\max } \\
\min \end{array}$ \\
\hline 60 & 2 & 0.238 & 0.224 & 0.252 & 11.2 & $12.5-13$ \\
\hline 110 & 9 & 0.242 & 0.235 & 0.480 & 5.8 & 8.5 \\
\hline 270 & 5 & 0.230 & 0.254 & 1.15 & 2.5 & $4-5.5$ \\
\hline
\end{tabular}
the more accurate spline integration procedure.

TABLE 8. Average main period characteristics, electrical calibration

\section{References}

[1] Dickinson, H. C., Bull. BS 11, 189 (1914).

[2] Jessup, R. S., J. Res. NBS 29, 247 (1942) RP1490.

[3] Jessup, R. S., NBS Monograph 7, February 26, 1960.

[4] Coops, J., Jessup, R. S., and Van Nes, K., Calibrations of Calorimeters for Reactions in a Bomb at Constant Volume, ch. 3, Experimental Thermochemistry, Vol. 1, F. D. Rossini, Editor (Interscience Publishers, Inc., New York, N.Y., 1956).

[5] Prosen, E. J. Compounds Containing Carbon, Hydrogen, Oxygen, and Nitrogen, ch. 6, Experimental Thermochemistry, Vol. I, F. D. Rossini, Editor (Interscience Publishers, Inc., New York, N.Y., 1956).

[6] Jessup, R. S., ibid, figures la, lb, and Appendix 7.1e.

[7] Jessup, R. S., ibid., Appendix 7.1d.

[8] Domalski, E. S., and Armstrong, G. T., J. Res. NBS 69A (Phys. and Chem.), No. 2, 137 (1965).

[9] Jessup, R. S., ibid., p. 20, figure 1c.

[10] Stimson, H. F., Precision Resistance Thermometry and Fixed Points, ch. 9, Temperature, Its Measurement and Control in Science and Industry, Vol. II, H. C. Wolfe, Editor, American Institute of Physics (Reinhold Publishing Corp., New York, 1955).

[11] Armstrong, G. T., Wong, P. K., and Kreiger, L. A., Rev. Sci. Instr. 30, 339-343 (1959).

[12] Jessup, R. S., ibid., Appendix 7.1c

[13] Boyd, R. H., Rev. Sci. Instr. 35, 1086, 1964.

[14] Pailthrope, R. M., and Riley, J. C., An Improved Technique for Establishing Resistance Ratios, ESI Bulletin No. 35 (Electro Scientific Industries, Portland, Oreg., November 1962).

[15] Mueller, E. F. and Stimson, H. F., J. Res. NBS 13, 699 (1934), RP739.

[16] Osborne, N. S., Stimson, H. F., Ginnings, D. C., J. Res. NBS 23, 197, 261 (1939), RP1228.

[17] Jessup, R. S., ibid, p. 7.

[18] Jessup, R. S. and Green, C. B., J. Res. NBS 13, 469 (1934), RP721.

[19] Jessup, R. S., NBS Monograph 7, Sec. 3.2 and 4.

[20] Hubbard, W. N., Scott, D. W., and Waddington, G., Standard States and Corrections for Combustions in a Bomb at Constant Volume, ch. 5, Experimental Thermochemistry, Vol. I, F. D. Rossini, Editor (Interscience Publishers, Inc., New York, N.Y., 1956).

[21] Walsh, J. H., Ahlberg, J. H., and Nilson, E. H., J. Math. and Mech. 11, (No. 2), 225 (1962).

[22] Darmouth Basic Library, Code: Spline, Converted to Basic Language by Messina, C., NBS, September (1965).

[23] Katsanis, T., NASA Technical Note, D-2546, December (1964).

[24] Shomate, C. H., Fortran IV Computer Program for Reduction of Heat of Combustion Calorimetric Data, Code 5052 (U.S. Naval Ordnance Test Station, China Lake, California, January 1967).

[25] Hamer, W. J., NBS Monograph 84, January 15, 1965.

[26] Ginnings, D. C., West, E. D., Principles of Calorimetric Design, ch. 4, Experimental Thermodynamics, Vol. I, Calorimetry of Non Reacting Systems, J. P. McCullough, Editor (Butterworth and Co., Ltd., In press).

[27] Rossini, F. D., Assignment of Uncertainties to Thermochemical Data, ch. 14, Experimental Thermochemistry, Vol. I, F. D. Rossini, Editor (Interscience Publishers, Inc., New York, N.Y., 1956).

[28] Ginnings, D. C., West, E. D., Rev. Sci. Instr. 35, 965 (1964).

[29] Harper, D. R., J. Res. NBS 8, 659 (1912).

[30] White, W. P., The Modern Calorimeter (Reinhold Publishing Corp., New York, 1928), p. 89, p. 36. See also J. Am. Chem. Soc. 40, 1861-1863, 1918 and Phys. Rev. 31, 568-570, 1910.

[31] Coops, J., Adriaanse, N., Van Nes, K., Rec. Trav. Chim. 75, 237 (1956).

[32] West, E. D., J. Res. NBS 67A (Phys. and Chem.), No. 4, 331 (1963).

[33] Jessup, R. S., J. Res. NBS 36, 421 (1946), RP1711.

[34] Challoner, A. R., Gundry, H. A., Meetham, A. R., Phil. Trans. Roy. Soc. (London), A247, 553 (1955).

[35] Prosen, E. J. and Rossini, F. D., J. Res. NBS 33, 439 (1944), RP1619.

[36] Mosselman, C., and Dekker, H., The Free University, Amsterdam, Private Communication.

[37] Head, A. J., Natl. Physical Laboratory, Teddington, private communication. 